\title{
Pyrolysis Optimization of Agricultural Waste Using Taguchi L9 Orthogonal Array Design
}

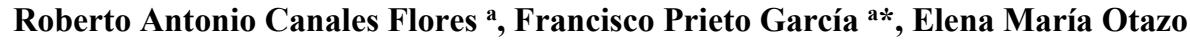 \\ Sánchez a , Ana María Bolarín Miró ${ }^{\mathrm{b}}$, Otilio Arturo Acevedo Sandoval a

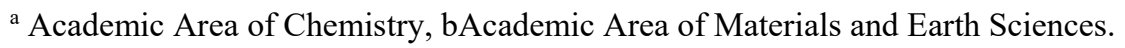 \\ Autonomous University of Hidalgo State, Road Pachuca-Tulancingo km 4.5, C.P. 42186. \\ Pachuca, Hidalgo, Mexico. \\ * Corresponding author. E-mail address: prietog@uaeh.edu.mx (F. Prieto García)
}

\section{Abstract}

This research demonstrates the optimization and production of biochar from barley husk (BH), corn cob (CC), and Agave salmiana leaves (AL) via pyrolysis in a muffle furnace. Taguchi experimental design (L9) was applied to conduct the experiments at different levels by altering four operating parameters. Carbonization temperature $\left(300-500{ }^{\circ} \mathrm{C}\right)$, carbonization time (30-90 min), precursor mass ( $2-5 \mathrm{~g})$ and $\mathrm{N}_{2}$ flow rate $(100-200 \mathrm{cc} / \mathrm{min})$ were the variables examined in this study. The effect of the parameters on the biochar yield was investigated, and the important parameters were identified employing analysis of variance (ANOVA). The optimum conditions for maximum biochar yield were: carbonization temperature of $400{ }^{\circ} \mathrm{C}$, carbonization time of $30 \mathrm{~min}$, precursor mass of $2 \mathrm{~g}$, and $\mathrm{N}_{2}$ flow rate of $150 \mathrm{cc} / \mathrm{min}$. The biochars produced under optimum conditions was characterized physically and chemically. Biochar yields of $19.75 \%$ for corn cob (CCB), $32.88 \%$ for barley husk (BHB), and $31.14 \%$ for agave leaves (ALB) were obtained.

\section{Statement of Novelty}

This is the first time reported the obtaining of activated carbon from barley husks and leaves of agave salmiana

Keywords: pyrolysis; biomass; biochar; Taguchi; optimization 


\section{Introduction}

Lignocellulosic biomass is a complex biological product and is considered as a promising alternative and a renewable energy source that can be transformed by thermal processes into other value-added products such as biochar and bio-oil. (Stefanidis et al., 2014; Tripathi et al., 2016).Significant researchers have been devoted to the production of carbonaceous materials from agricultural waste (Ioannidou and Zabaniotou, 2007). Wood, corn straw, olive stones, bagasse, sugar cane bagasse, almond shells, corn stover, apricot stones, nut shells, corn cob, rice husk and rice straw are some examples of biomass used for obtaining biochar (Canales-Flores and Prieto-García, 2016).

Conversion of biomass into biochar can be made mainly by two methods: pyrolysis and gasification (Ahmad et al., 2014). Of the two methods mentioned, pyrolysis is the most used method to produce biochar from the biomass (Canales-Flores and Prieto-García, 2016; Tripathi et al., 2016). On the gasification method, the biomass is heated to temperatures above $700{ }^{\circ} \mathrm{C}$ to obtain gases rich in carbon monoxide and hydrogen, under controlled oxygen or vapor conditions (Ahmad et al., 2014). In contrast, on the pyrolysis, the lignocellulosic material is thermally degraded at temperatures in the range of $200-900{ }^{\circ} \mathrm{C}$ under an inert atmosphere to produce biochar, bio-oil, and gas (Ahmad et al., 2014; Tripathi et al., 2016). Biochar is one of the by-products obtained from the thermal degradation of lignocellulosic matter(Tripathi et al., 2016), and it is descriptivelydefinedbyShackley et al. (2012)as "the porous carbonaceous solid produced by the thermochemical conversion of organic materials in an oxygen depleted atmosphere that has physicochemical properties suitable for safe and long-term storage of carbon in the environment."

According to Tripathi et al. (2016), the production of biochar from biomass does not only depend upon the technique employed to produce, but it is also a function of the process parameters. Research on the pyrolysis has revealed that the production, yield, and properties of the biochar depend upon several factors like biomass properties (moisture content and particle size), reaction conditions (temperature, time, and heating rate) and another factors (flow rate of carrier gas, catalyst, and reactor type) (Tripahi et al., 2016). These authors also indicate that itto achieve maximum yield of biochar, the process parameters of the biomass pyrolysis have to be optimized. 
66 Biochar production from biomass requires consideration of various factors. The use of 67 statistical designs of experiments has been implemented in several optimization studies to determine which factors affect the process and to reduce the number of trials significantly (Loloide et al., 2016; Syed-Hassan and Md Zaini, 2016). Taguchi methodology is widely used in the design and optimization of experiments and uses orthogonal arrays to organize control factors and the levels at which each factor is evaluated (Syed-Hassan and Md Zaini, 2016). Taguchi design evaluates pairs of combinations to determine the optimum levels that contribute to optimum response value taking into account the mean value, the variance and the signal-to-noise (S/N) ratio (Syed-Hassan and Md Zaini, 2016). In this study, Taguchi orthogonal array design was implemented as a systematicmethod to obtainoptimum conditions for the preparation of biochar by pyrolysis of barley husk, corn cob, and agave leaves. This design was employed with the objective ofmaximizing the biochar yields. The effect of the process parameters such as carbonization temperature process time, precursor mass, and $\mathrm{N}_{2}$ flow rate, was examined. Comparisons of biochar's physical and chemical characteristics were also made.

\section{Materials and methods}

\subsection{Preparation of precursors}

Barley husk (BH), corn cobs (CC), and Agave salmiana leaves (AL) were the lignocellulosic residues used a biochar precursors in this study. These precursors were obtained from Almoloya and Apan in the State of Hidalgo, Mexico. The raw materials were washed five times with distilled water, titrated in a food processor, dried at $105^{\circ} \mathrm{C}$ for $72 \mathrm{~h}$ in an oven, ground in a knife mill to obtain $0.3-1.0 \mathrm{~mm}$ particle size and finally sieved through 18 and 45 mesh sieves. The chemical composition of $\mathrm{BH}, \mathrm{CC}$, and $\mathrm{AL}$ is summarized in Table 1. Chemical characterization of the precursors was carried out according to the method described in ASTM Standard D3172 (1997), total sugars and fat according to the TAPPI T204 (1997), Klason lignin according to the TAPPI T222 (1998),

94 holocellulose according to the method described by Wise et al. (1946), and $\alpha-, \beta$ - and $\gamma$ cellulose according to the TAPPI T203 (1999). 
97 Table 1. Chemical composition of precursor (\%wt.)

\begin{tabular}{lrrrrrrl}
\hline Precursor & Lignin & $\alpha$-cellulose & $\beta$-cellulose & $\gamma$-cellulose & Holocellulose & Sugars & Fat \\
\hline BH & 26.46 & 66.69 & 22.38 & 10.92 & 82.07 & 27.44 & 2.06 \\
CC & 15.24 & 52.60 & 44.52 & 2.89 & 82.38 & 19.34 & 0.82 \\
AL & 15.58 & 79.45 & 13.18 & 7.37 & 83.05 & 42.29 & 1.68 \\
\hline
\end{tabular}

98

99

100

101

102

103

104

105

106

107

108

109

$110 \quad$ Yield $(\%)=\frac{\mathrm{W}_{2}}{\mathrm{~W}_{1}} \times 100$

112 where $\mathrm{W}_{1}$ is the initial weight of the precursor $(\mathrm{g})$, and $\mathrm{W}_{2}$ is the weight of the obtained 113 biochar $(\mathrm{g})$.

114

\subsection{Taguchi experimental design}

116 Experimental design is a powerful approach for the optimizationof parameters. Taguchi

117 methodis one of the most tried-and-true, fastest techniques for design ofexperiments and 118 response optimization. The Taguchi design is based on testing the sensitivity of a set of 119 response variables to a set of control parameters by considering experiments in an 120 orthogonal array with an aim to attain the optimum setting of the control parameters or 121 factors. In this research L9 orthogonal array with four operational parameters known as 122 control factors, namely carbonization temperature $\left({ }^{\circ} \mathrm{C}\right)$, carbonization time $(\mathrm{min})$, precursor 123 mass $(\mathrm{g})$ and $\mathrm{N}_{2}$ flow rate (cc/min), with three levels for each as shown in Table 2 . In the 
124 Taguchi method, there are three main types of $\mathrm{S} / \mathrm{N}$ ratio, which are smaller the better, 125 nominal the best, and larger the better. Since the aim of this study is to obtain the value of 126 response (biochar yield) as high as possible, the larger the better is used. Noise factor taken 127 in this study is the raw material. BH is considered as the noise factor $1, \mathrm{CC}$ is taken as noise 128 factor 2, and $\mathrm{AL}$ is considered as noise factor 3. Table 3 shows the L9 orthogonal array 129 including the noise factors. The design matrix was provided by ANTM 2.5, a statistical 130 software which incorporates Taguchi's L9 Orthogonal Array Method. This software was 131 also used in the computation of the ANOVA.

132

133 Table 2. Control factors and their levels.

\begin{tabular}{lccc}
\hline Process parameters & Level 1 & Level 2 & Level 3 \\
\hline Factor A: Carbonization temperature $\left({ }^{\circ} \mathrm{C}\right)$ & 300 & 400 & 500 \\
Factor B: Carbonization time (min) & 30 & 60 & 90 \\
Factor C: Precursor mass $(\mathrm{g})$ & 2 & 3 & 5 \\
Factor D: $\mathrm{N}_{2}$ flow rate (cc/min) & 100 & 150 & 200 \\
\hline
\end{tabular}

136 Table 3. Orthogonal array (L9) of Taguchi experimental design with the noise factors and 137 the measured yield value of biochar.

\begin{tabular}{|c|c|c|c|c|c|c|c|}
\hline \multicolumn{5}{|c|}{ Inner control factor control array } & \multirow{2}{*}{\multicolumn{3}{|c|}{$\begin{array}{l}\text { Outer noise factor array } \\
\text { Yield (\%wt.) }\end{array}$}} \\
\hline \multirow{2}{*}{ Run } & \multicolumn{4}{|c|}{ Process parameters } & & & \\
\hline & $\begin{array}{c}\text { Factor A } \\
\left({ }^{\circ} \mathrm{C}\right)\end{array}$ & $\begin{array}{c}\text { Factor B } \\
\text { (min) }\end{array}$ & $\begin{array}{c}\text { Factor C } \\
(\mathrm{g})\end{array}$ & $\begin{array}{l}\text { Factor D } \\
\text { (cc/min) }\end{array}$ & BHB & $\mathrm{CCB}$ & ALC \\
\hline 1 & 300 & 30 & 2 & 100 & 34.49 & 18.36 & 39.3 \\
\hline 2 & 400 & 60 & 3 & 200 & 19.10 & 5.16 & 15.43 \\
\hline 3 & 500 & 90 & 5 & 150 & 16.21 & 3.20 & 33.04 \\
\hline 4 & 300 & 60 & 3 & 200 & 33.87 & 9.87 & 34.15 \\
\hline 5 & 400 & 90 & 2 & 150 & 19.71 & 3.46 & 18.73 \\
\hline 6 & 500 & 30 & 5 & 100 & 26.02 & 13.7 & 21.99 \\
\hline 7 & 300 & 90 & 5 & 200 & 25.61 & 9.15 & 26.47 \\
\hline 8 & 400 & 30 & 2 & 150 & 26.67 & 4.76 & 29.48 \\
\hline 9 & 500 & 60 & 3 & 100 & 17.04 & 3.94 & 17.71 \\
\hline
\end{tabular}

138 
140

141

142

143

144

145

146

147

148

149

150

151

152

153

154

155

156

157

158

159

160

161

162

163

164

165

166

167

168

169

170

\subsection{Characterization of biochar}

The optimum biochars were characterized according to the method described in ASTM Standard D3172 (1997). Elemental analyses of C, H, and N was carried out by a Perkin Elmer analyzer model 2400 PECHN-SO using acetanilide as the reference. The oxygen content was obtained indirectly by difference. The thermal behavior was performed with a Mettler-Toledo analyzer model TGA/SDTGA-851, under a nitrogen atmosphere, with a heat ramp of $10{ }^{\circ} \mathrm{C} / \mathrm{min}$ up to $600{ }^{\circ} \mathrm{C}$. Besides, the biochars were analyzed by Fourier Transform infrared spectrophotometry (FTIR) on a Perkin Elmer Spectrum one spectrometer. The spectra were recorded in the region of 4000 to $370 \mathrm{~cm}^{-1}$, resolution of 4 $\mathrm{cm}^{-1}$ and ten scans. The surface morphology of the precursors was observed by scanning electron microscopy (SEM) using a JEOL scanning electron microscope model JSM 6300 operated at $10 \mathrm{kV}$. For observation, particles of the precursors were dispersed onto carbon tape and coated with gold. X-ray powder diffraction (XRD) in a Bruker D2 Phaser 2nd Gen, for values of $2 \theta$ from $5^{\circ}$ to $70^{\circ}$ using $\mathrm{Cu} K \alpha$ radiation $(1.54184 \AA$ ), and a detector Lynxeye (ID mode).The pore distribution was determined by mercury porosimetry in a porosimeter Model AutoPore IV 9500 with detection range of $0.003 \mu \mathrm{m}$ to $360 \mu \mathrm{m}$, and potential Z on a Malvern Zetasizer nanoseries.

\section{Results and discussion}

3.1. Analysis of variance (ANOVA) of $\mathrm{S} / \mathrm{N}$ ratio and effects of the control factors on the biochar preparation

According to Taguchi orthogonal array, twenty-seven different biochars were prepared. Table 3 shows the yield results of biochar for each run, and are used to predict the optimum condition for the process pyrolysis. Yield results between 16 to $34 \%$ for BHB, from 3 to $18 \%$ for $\mathrm{CCB}$, and from 15 to $39 \%$ for ALB were obtained. The $\mathrm{S} / \mathrm{N}$ ratio was tested by ANOVA to determine the relative significance of the $\mathrm{S} / \mathrm{N}$ data obtained for the process parameters. According to Kundu et al. (2014), ANOVA determines the impact of the independent variableson the dependent variables in a regression analysis. The ANOVA results for $\mathrm{S} / \mathrm{N}$ ratio are given in Table 4 . Effects of control factors on the $\mathrm{S} / \mathrm{N}$ ratio of the biochar yields can be observed in Figure 1.Bold values in Table 4 for the level averages are 
171 the maximum average S/Nperformances of factors in the four different levels at each 172 factor.F-value indicates the statistical calculation on the effects of control factor to the 173 response. The F-value is obtained by comparing the variance associated with the residual 174 variance. The factor with high F-value is themost important factor affecting the yield of 175 biochar. According to Kirby (2006), a F-ratio lessthan one suggests insignificant effect, a 176 value near about two suggestsmoderate effect and if the F-ratio is more than four, 177 thecontrol factors have a strong and significant effect on the response. Therefore, Table 4 178 shows that the carbonization time and the precursor mass have a significant effect on the 179 preparation of biochar whereas the $\mathrm{N}_{2}$ flow rate and the carbonization temperature have a 180 moderate effect. The $\mathrm{S} / \mathrm{N}$ ratio for the carbonization time increases as the level decreases 181 from $90 \mathrm{~min}$ to $30 \mathrm{~min}$, meaning that the biochar yield increased. However, when the 182 carbonization time was higher than $30 \mathrm{~min}$, the $\mathrm{S} / \mathrm{N}$ ratio decreased, indicating that the 183 biochar yield decrease. Prías-Baragán et al. (2011) found that low temperatures with 184 extended carbonization times are required to improve activated carbon production.It means 185 that by increasing the carbonization times, it is promoted to the repolymerization of the 186 constituents of the biomass by giving them sufficient time to react.On the other hand, if the 187 carbonization times are very short, the repolymerization of the components of the biomass 188 will not be completed, and the biochar yields will be decreased. The $\mathrm{S} / \mathrm{N}$ ratio indicated that 189 the optimum level for the carbonization time is the level 1 which corresponds to 30 190 min.Practically no change wasobserved in the $\mathrm{S} / \mathrm{N}$ ratio for the last two levels of 191 carbonization time of $60 \mathrm{~min}$ and $90 \mathrm{~min}$.During the experimentation, it was observed that increasing the carbonization time with high temperatures resulted in a decrease in biochar yield.Thus, the shorter carbonization time in combination with moderate temperatures had a very significant effect for obtaining higher biochar yields. The increase in the biochar yield at the first level of carbonization time was due to the release of the volatile components

196 from the precursors is gradual, and the repolymerization reactions take place(Tripathi et al., 197 2016). 
202 Table 4. ANOVA S/N ratios for the prepared biochars.

\begin{tabular}{|c|c|c|c|c|c|c|c|c|c|}
\hline \multirow{2}{*}{ Source } & \multirow{2}{*}{$\mathrm{DF}^{\mathrm{a}}$} & \multirow{2}{*}{$\mathrm{S}^{\mathrm{b}}$} & \multirow{2}{*}{$\mathrm{V}^{\mathrm{c}}$} & \multirow{2}{*}{$\mathrm{F}$} & \multirow{2}{*}{$\mathrm{S}^{\prime d}$} & \multirow{2}{*}{$\mathrm{P}^{\mathrm{e}}(\%)$} & \multicolumn{3}{|c|}{ Level average } \\
\hline & & & & & & & Level 1 & Level 2 & Level 3 \\
\hline Factor $\mathrm{A}\left({ }^{\circ} \mathrm{C}\right)$ & 2 & 8.60 & 4.30 & & & & 20.41 & 21.52 & 19.12 \\
\hline Factor B (min) & 2 & 105.01 & 52.50 & 12.21 & 96.40 & 50.23 & 25.10 & 17.22 & 18.74 \\
\hline Factor C (g) & 2 & 61.26 & 30.63 & 7.12 & 52.65 & 27.43 & 23.88 & 19.51 & 17.66 \\
\hline Factor D (cc/min) & 2 & 17.07 & 8.53 & 1.98 & 8.46 & 4.41 & 19.94 & 22.21 & 18.91 \\
\hline Residual error & 2 & 8.60 & 4.30 & & 34.40 & 17.93 & & & \\
\hline
\end{tabular}

$203{ }^{a}$ DF: degree of freedom.

204 b S: standard deviation.

$205{ }^{c} \mathrm{~V}$ : variance $\left(\mathrm{S}^{2}\right)$.

$206 \mathrm{~d}^{\mathrm{d}}$ ': standard deviation recalculated by neglecting the smallest variance.

207 e P: contribution percentage at each factor.

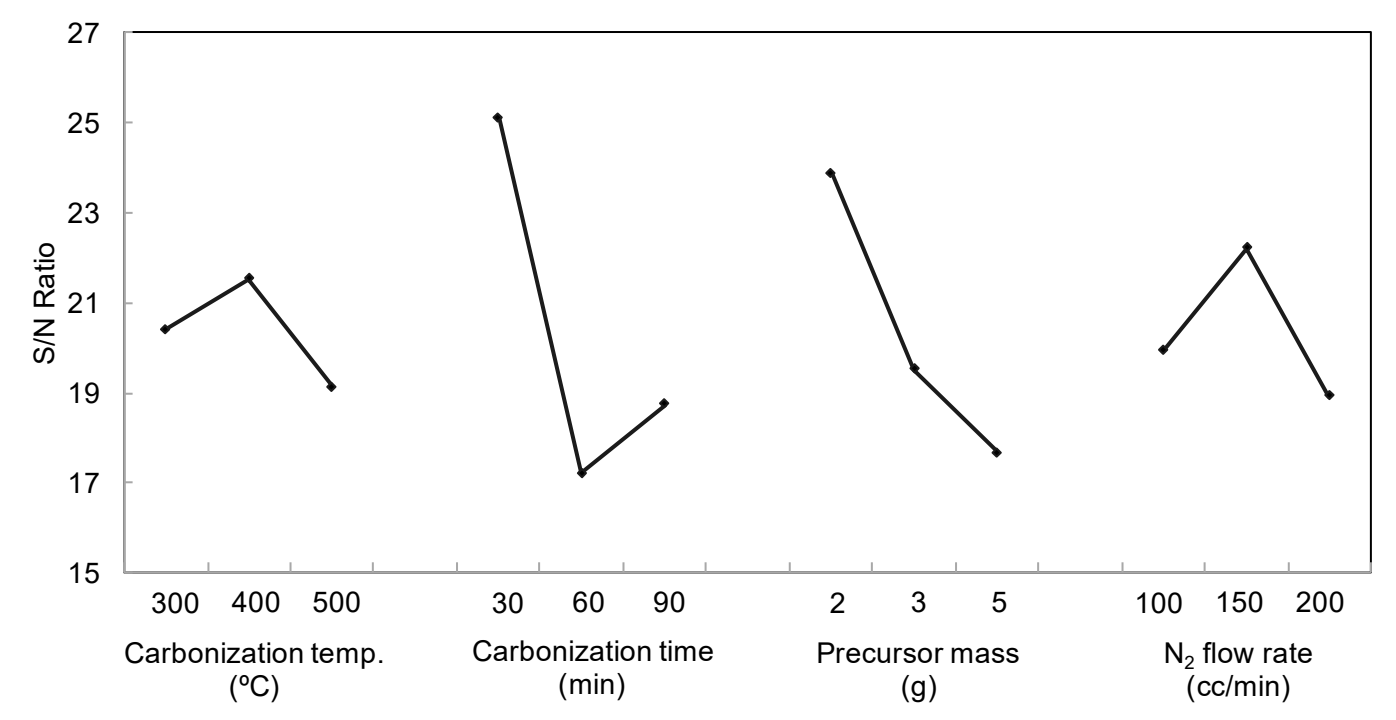

Figure 1. Effect of the control factors on the $\mathrm{S} / \mathrm{N}$ ratio of the biochar yield.

213 The literature also mentions that the effect of the carbonization time is directly related to

214 other process parameters such as the carbonization temperature and the heating rate. Table

2154 shows the $\mathrm{S} / \mathrm{N}$ ratio for the carbonization temperature which increases the biochar yield in

216 the level 2 which corresponds to $400{ }^{\circ} \mathrm{C}$. This carbonization temperature was the best for

217 obtaining the highest carbon yieldsbecause high temperatures promotethe thermal cracking

218 of heavy hydrocarbons present in the precursorincreasing the liquid and gaseous products,

219 and the decrease of biochar yield (Tripathi et al., 2016). These findings are consistent with

220 those reported byAteş et al. (2004) who showed that a temperature increase of 400 to 700 
$221{ }^{\circ} \mathrm{C}$ caused a 17\% reduction in the yield of biochar for sesame stems. Choi et al. (2012) also

222 reported the decrease of the biochar yield with increasing pyrolysis temperature.

223 Table 1 shows that the three precursors presented high contents of $\alpha$-cellulose and low 224 contents of lignin, with values of $52.60-79.45 \%$ and $15.58-26.46 \%$, respectively. The 225 literature indicates that, during pyrolysis processes, low temperatures are suitable for 226 cellulose-rich precursors, because at high temperatures $\left(>800{ }^{\circ} \mathrm{C}\right)$ cellulose leads to the 227 formation of volatile products while at low temperatures $\left(450-600{ }^{\circ} \mathrm{C}\right)$. It is lead to the 228 formation of biocharsince the cellulose is degraded to anhydrocellulose resulting in the high 229 production of biochar. Therefore, carbonization temperature of $400{ }^{\circ} \mathrm{C}$ was adequate to 230 obtain higher biochar yields.

231 The rate of entrainment gas flow is another important parameter in the pyrolysis 232 process. The $\mathrm{S} / \mathrm{N}$ ratio indicated that $150 \mathrm{cc} / \mathrm{min}$ is the optimum level for the $\mathrm{N}_{2}$ flow 233 rateduring the pyrolysis process. This result is consistent with studies by Sensöz and Angin 234 (2008), who found that biochar yield decreased with increased the rate of nitrogen flow 235 during the pyrolysis process of safflower seeds. They concluded that once the flow of 236 nitrogen exceeds $100 \mathrm{cc} / \mathrm{min}$, the yield of biochar remains almost constant. Zhang et al. 237 (2009) found that there is no noticeable change in biochar yield by increasing the nitrogen 238 flow rate above $2.3 \mathrm{~L} / \mathrm{min}$. The studies by Onay et al. (2001) and Pütün et al. (2002) found 239 that there is no significant change in biochar yield by increasing the nitrogen flow rate 240 above $50 \mathrm{cc} / \mathrm{min}$. These findings indicate that a low nitrogen flow rate is sufficient to take 241 most of the vapors out of the reaction zone resulting in high biochar yields. Therefore, a $\mathrm{N}_{2}$ 242 flow of $150 \mathrm{cc} / \mathrm{min}$ is suitable for the process since, according to the authors, high flow 243 rates of nitrogen are not necessary to obtain high biochar yields.

244 Concerning the effect of the mass of the precursor, it was found that $2 \mathrm{~g}$ is the optimal 245 condition for obtaining the higher yield of biochar since with this amount of precursor the 246 release of the volatile components is optimal in combination with short carbonization times 247 (30 minutes).

\subsection{Optimization of the process parameters}

250 In this study, the "larger the better" type ofanalysis was selected as the response since the 251 highest biochar yield is alwaysdesirable. The largest $\mathrm{S} / \mathrm{N}$ ratio corresponds to the optimum 
252 characteristics. Table 4 shows the mean $\mathrm{S} / \mathrm{N}$ ratio for each level of the control factors,

253 which wassummarized as $\mathrm{S} / \mathrm{N}$ response. As can be seen in Figure 1, the optimum condition

254 is the following:carbonization temperature of $400{ }^{\circ} \mathrm{C}$ (level 2), process time of $30 \mathrm{~min}$ 255 (level 1), precursor mass of $2 \mathrm{~g}$ (level 1), and $\mathrm{N}_{2}$ flow rate of $150 \mathrm{cc} / \mathrm{min}$ (level 2). For the 256 additional study, biochar samples were prepared by confirmatory experiments using these 257 levels for the control factors. Biochar yields of $19.75 \%$ for $\mathrm{CCB}, 32.88 \%$ for $\mathrm{BHB}$, and $25831.14 \%$ for ALB were obtained under optimum conditions. These biochars were 259 characterized physically and chemically.

\subsection{Characterization of the biochars obtained under optimum conditions}

262 According to Nieto-Delgado et al. (2011) to consider a raw material as a good precursor to 263 produce activated carbon must possess certain characteristics such as low cost, availability, 264 high carbon content, low content of inorganic compounds, and the existence of a natural 265 porosity. Figure 2 shows the results of proximal analysis of biocharscompared with the 266 precursors. As illustrated, the moisture content of the precursors was the same, around 7\%, 267 and for the biochars was less than 4\%. Tripathi et al. (2016) mention that low moisture is 268 advisable for the activated carbon production because it not only reduces the heat energy 269 but it also lowers the time required for the process. Specifically, lignocellulosic precursors 270 with more than $30 \%$ of moisture are not suitable for the pyrolysis since the greater amount 271 of energy supplied to the biomass would be used in moisture removal present in it and rest 272 would be used to increase its temperature. They also indicate that a significant amount of 273 moisture (more than $40 \%$ ) reduces the heating rate resulting in more time in achieving the 274 process temperature. Demirbas (2004) and Xiong et al. (2013) observed that increase in 275 moisture content in pyrolysis of wood and sewage sludge, respectively, decreases the yield 276 of biochar. Therefore, the moisture content of the three precursors of this study was suitable 277 for the biochar production under optimum conditions.

278 Ash content is another important parameter in the activated carbon production since it 279 defines the quality of precursor in the combustion determining the content of incombustible 280 matter and it is related to the dissolution of salts generating problems of pollutantsin 281 aqueous mediawhen the activated carbon is used. (Nieto-Delgado et al., 2011). Thus, a low 282 ash content is desired because it could negatively affect the yields to partially eliminate the 
283 formation of char (Pereira et al., 2014).In this research, the ash contents of precursors are 284 less than $10 \%$ and are acceptable for the activated carbons production. In contrast, the ash 285 content of CCB and ALB was the same, around 33\%. However, the ash content of BHB 286 was higher, about $45 \%$. In this case, we established that the yield of the BHB is masked by 287 the high content of inorganic compounds.It is attributed to the fact that barley by holding 288 the grass family has a natural tendency to absorb a significant amount of silicon (Espino et 289 al., 2014), which is concentrated after the heat treatment.

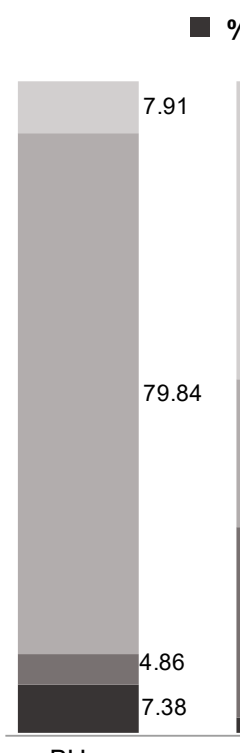

$\mathrm{BH}$
\%Moisture

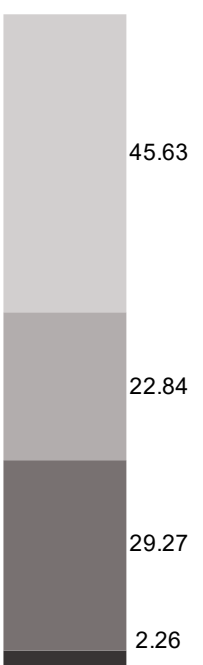

BHB

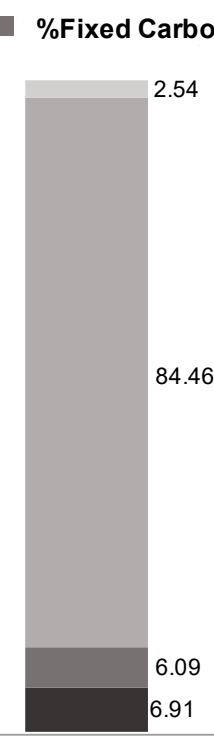

$\mathrm{CC}$

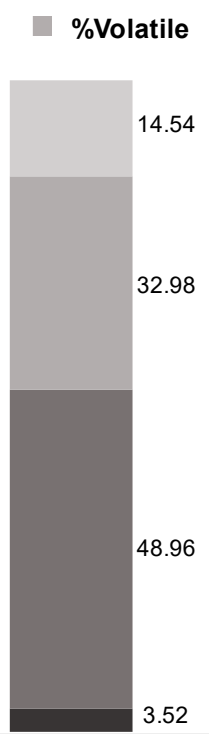

ССB

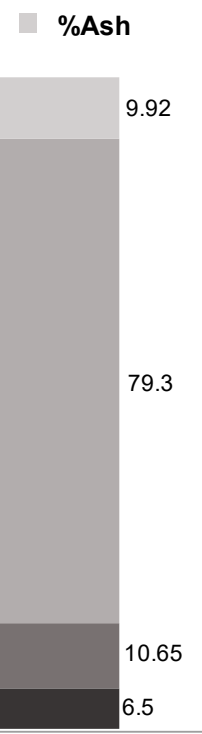

$\mathrm{AL}$

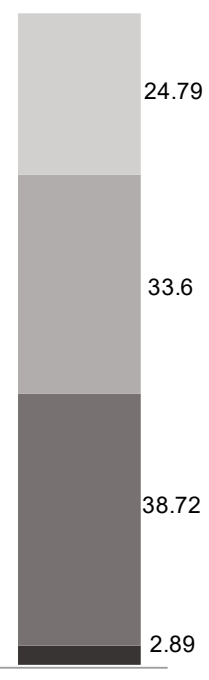

ALB

292 Figure 2. Proximal analysis of biochars obtained under optimum conditions and precursors.

294 Regarding the content of volatile matter, the volatile matter content is another important 295 parameter because it indicates the reactivity and ease of ignition of an organic material 296 (Canales-Flores and Prieto-García, 2016).In this study, high volatile contents were found on 297 the precursors with values from $79 \%$ to $84 \%$. These values are very suitable for the process pyrolysis since the gradual and controlled release of volatile matter, result in the enrichment of carbon (Canales-Flores and Prieto-García, 2016). In contrast, contents of volatile matter 300 from $22 \%$ to $33 \%$ were determined for the biochars. These results are lower than those of 301 the raw materials. This tendency was to be expected since the gradual and controlled loss of volatile matter under optimum conditions, produced the carbon enrichment in the biochar 
303 obtained, mainly in CCB (48.96\%) and ALB (38.72) as shown in Figure 3. The BHB

304 showed the lowest carbon enrichment due to its high content of inorganic material.

305

306

307

308

309

310

311

312

313

314

315

316

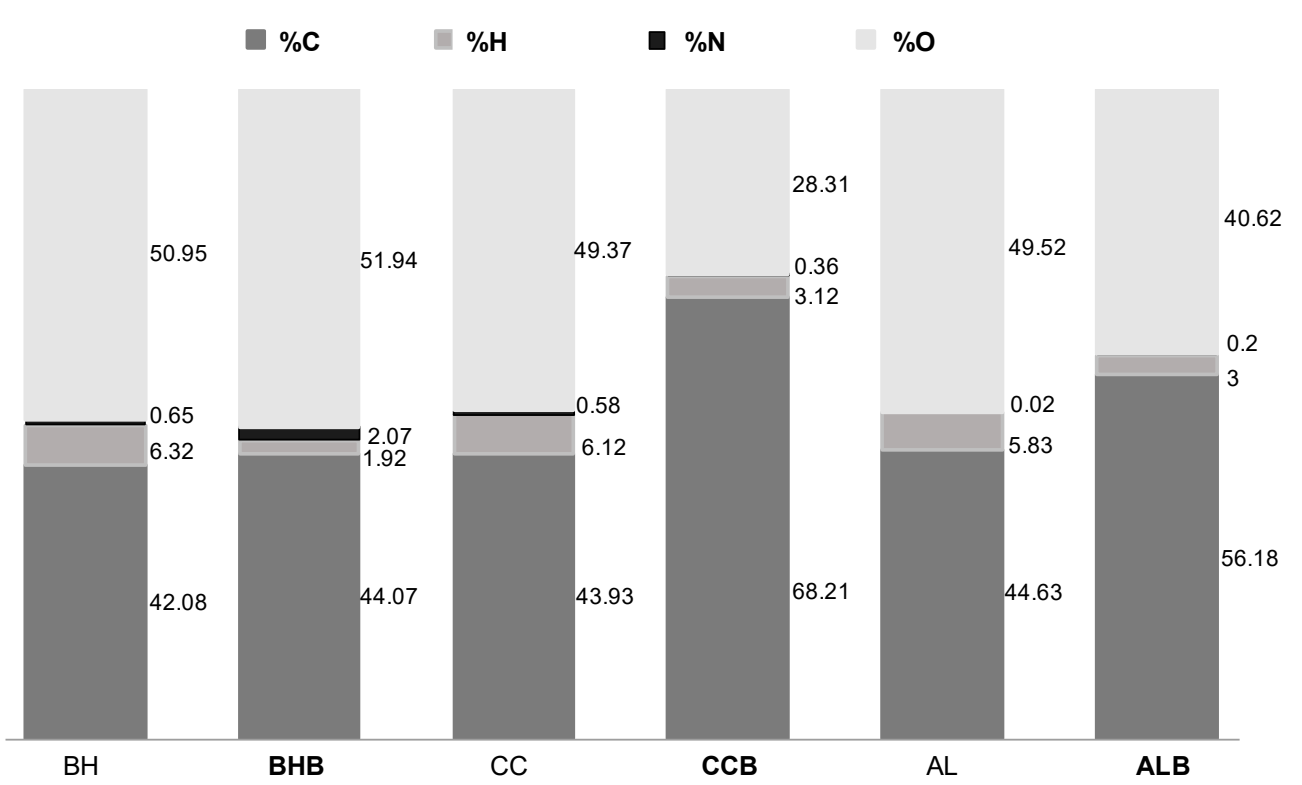

Figure 3. Elemental analysis of biochars obtained under optimum conditions and precursors.

\subsection{Fourier-transform infrared spectroscopy (FTIR)}

FT-IR spectra of the $\mathrm{BH}$ compared with $\mathrm{BHB}, \mathrm{CC}$ compared with $\mathrm{CCB}$, and $\mathrm{AL}$ compared with ALB are shown in Figure 4A-C. The intenseband is appearing at $3400 \mathrm{~cm}^{-1}$ in all samples, was attributed to stretching vibrations, characteristic of the hydroxyl functional group $(\mathrm{O}-\mathrm{H})$ belonging to the cellulose structure, which is themajor component of the precursors. The band characteristic of the methyl group resultant of $(\mathrm{C}-\mathrm{H})$ asymmetric and symmetric stretching was assigned to olefiniccompounds, which suggests an aliphaticity in the structure of the precursors. It was observed that the three precursors present diverse functionalgroups such as esters, ethers, alcohols, aldehydes, ketones, phenolsand carboxylic acids. Thus, in the double bond region, a shoulder peak at $1733 \mathrm{~cm}^{-1}$ for $\mathrm{BH}$, at $1737 \mathrm{~cm}^{-1}$ for $\mathrm{CC}$, and at $1731 \mathrm{~cm}^{-1}$ for $\mathrm{AL}$, were assigned to the $\mathrm{C}=\mathrm{O}$ stretching of the acetyl and uronic ester groups of hemicellulose, and to the ester linkage of carboxylic group of the $p$ coumaric acid of lignin. 
323 These bands disappeared in the spectra of the three biochars (Figure 4A-C). In contrast, It 324 can be observed that there are few differences about the peak assigned to the primary 325 amines in both precursor and biochars. Bledzki et al. (2010) mention that the exact 326 frequency of this vibration depends on the nature of the hydrogen bonds in the $\mathrm{C}=\mathrm{O}$ and $\mathrm{N}$ $327 \mathrm{H}$ groups. Thus, a peak at $1626 \mathrm{~cm}^{-1}$ (more intense) for BHB (Figure 4A), at $1595 \mathrm{~cm}^{-1}$ 328 (low intensity) for CCB (Figure 4B) and at $1612 \mathrm{~cm}^{-1}$ (shoulder) for ALB (Figure 4C) were 329 observed.

330 Bands in the range of $1375-1350 \mathrm{~cm}^{-1}$ were assigned to the symmetrical and asymmetric 331 deformations of $\mathrm{C}-\mathrm{H}$ in methyl and phenolic alcohol. The bands at $1458 \mathrm{~cm}^{-1}$ for BHB, 332 from 1379 to $1053 \mathrm{~cm}^{-1}$ for CCB, and from 1418 to $1059 \mathrm{~cm}^{-1}$ for ALB, were assigned to 333 deformation vibrations of $\mathrm{C}-\mathrm{C}$ in aromatic rings, as well as to the vibrations of $\mathrm{C}-\mathrm{O}$ and $\mathrm{C}$ 334 H. According to Bohli et al. (2015), this region is indicative of the carbon enrichment after 335 heat treatment.

336 A sharp peak at around $900 \mathrm{~cm}^{-1}$, characteristic of $\beta$-glycosidic linkages between the sugar 337 units of the cellulose (Bledzki et al., 2010), disappeared in the three biochars as a result of 338 pyrolysis. As can be seen, this region of bands, characteristic of the components of the 339 cellulose, presented substantial changes after obtaining the carbonaceous materials under 340 optimum conditions.

341 Analyzing the spectrum of the BHB sample, it can be observed that there are three major 342 differences about the spectrum of the CCB and ALB, associated with intense peaks at 1091 $343 \mathrm{~cm}^{-1}, 796 \mathrm{~cm}^{-1}$, and $450 \mathrm{~cm}^{-1}$. The first two bands are indicative of the vibrations of the Si344 O-Si bond bonds, and the third is assigned to the flexion of the O-Si-O bonds (Shen et al., 345 2014). This finding is consistent with that reported by Azizi et al. (2013) who mention that 346 in the FTIR spectrum of barley husk, the vibration and stress bands of Si-O-Si appear in the 347 regions of $420-500 \mathrm{~cm}^{-1}$ and $950-1250 \mathrm{~cm}^{-1}$. The presence of these bands in BHB is due to 348 the high inorganic content of the precursor, which is consistent with the findings of Azizi et 349 al. (2013) and Shen et al. (2014), who report silica content of $80 \%$ for barley husk and $60 \%$ 350 for rice husk, respectively. 

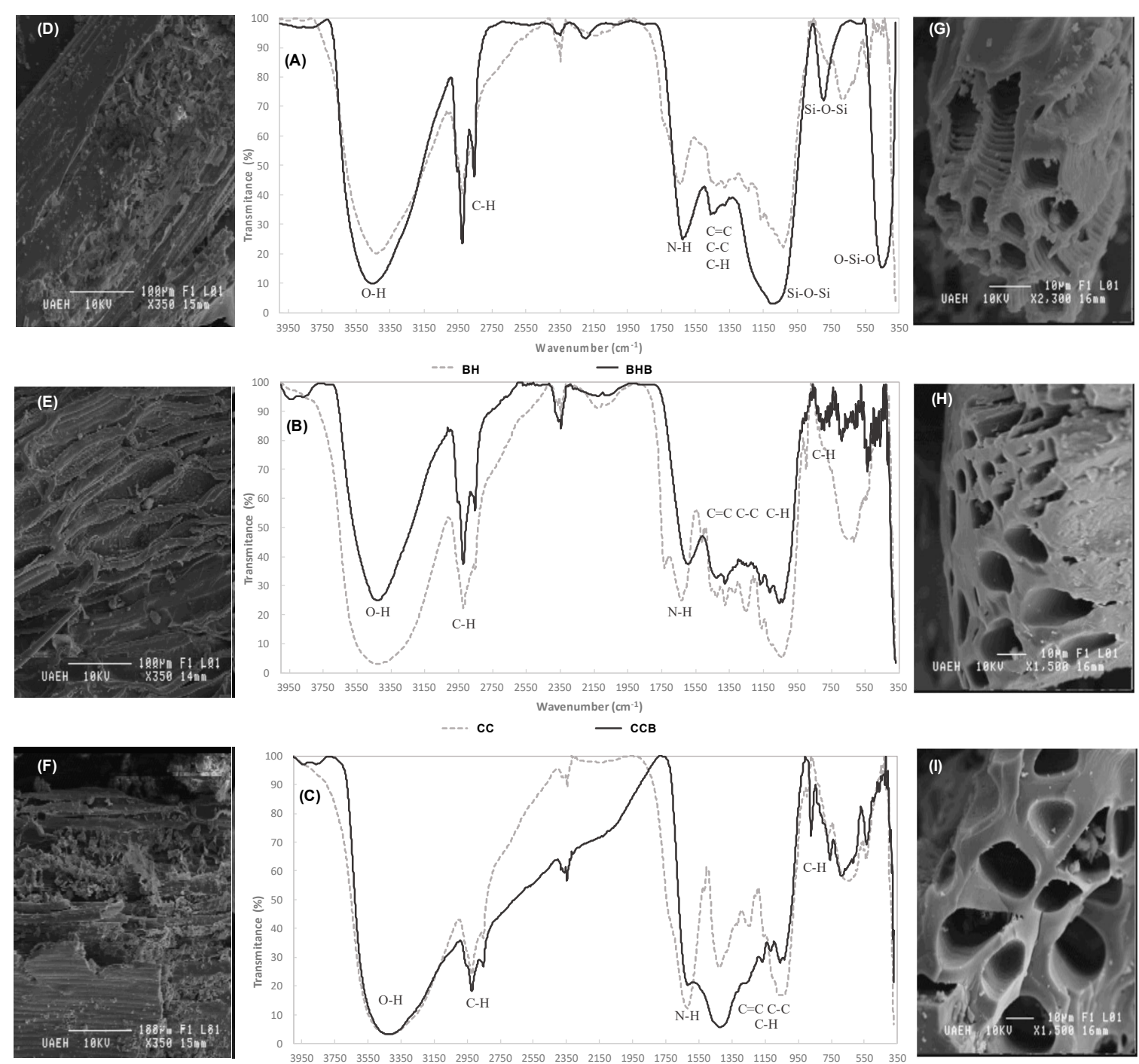

$$
\text { -... cc }
$$
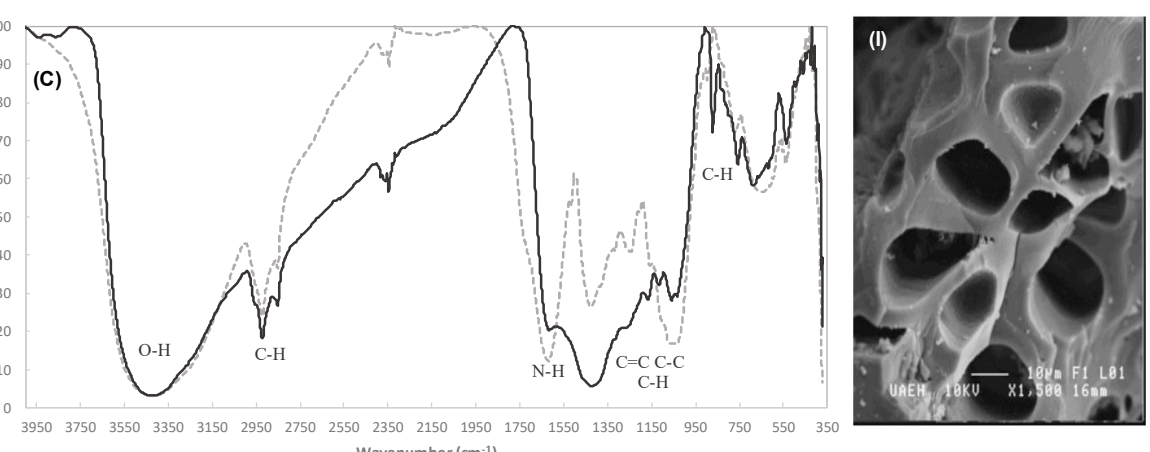

AL

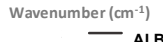

353 Figure 4. FTIR spectrum of biochars compared with the precursors (A, B, and C). SEM 354 micrographs of precursors (D, E, and F) and biochars ( $\mathrm{G}, \mathrm{H}$, and $\mathrm{I})$.

\subsection{Scanning electron microscopy (SEM)}

357 The morphological changes of the biomass samples, before and after the pyrolysis were

358 observed by scanning electron microscopy.Figure 4 shows the surface morphology of the 359 raw materials (Figure 4D-F) and the biochars (Figure 4G-I). It can be observed that three

360 lignocellulosic residues have fibrous and porous structure, which are suitable characteristics 361 to obtain carbonaceous materials such as activated carbons (Canales-Flores and Prieto- 
362 García, 2016) since biomass can readily decompose and burn. According to the literature, a 363 good precursor of activated carbon must have a porous and fibrous structure, since under 364 this condition, the oxygen can quickly diffuse inside the particle during combustion, and 365 volatile material can be gradually released (Gani and Naruse, 2007). Besides, from the 366 results of the micrographs of the biochars, it is established that the morphology of the 367 biochars obtained depends strongly on the precursor used. Thus, SEM images of the three 368 coals showed the formation of irregular shape and size cavities. It was observed that 369 biochar prepared from BH (Figure 4G) shows eroded particles composed of a large number 370 of channels and some smaller particles adhered to its surface. For CCB, Figure 4H shows 371 irregularly shaped channels with small holes of irregular size and the presence of smaller 372 particles adhered to their surface which occurred as a result of the combustion of the 373 precursor. In Figure 4I, it can be seen that in the ALB channels of regular shapes and 374 variable sizes were obtained.

\section{3.6. Mercury porosimetry}

377 From the results achieved from the micrographs, Figure 5 shows the pore size distribution 378 curves for BHB, CCB, and ALB. The pore sizes were classified according to the pore 379 radius (micropores 1-20 , mesopores 20-500 , macropores 500-50000 $\AA \AA$ ). When we 380 compared the pore size distribution curves for the three biochars, we observed the 381 predominance of macroporous structures in the three carbonaceous materials. As shown in 382 Figure 5, the ALB presented the highest volume of macropores with $0.045 \mathrm{~cm}^{3} / \mathrm{g}$, followed 383 by $\mathrm{CCB}$ with $0.037 \mathrm{~cm}^{3} / \mathrm{g}$, and $\mathrm{BHB}$ with $0.031 \mathrm{~cm}^{3} / \mathrm{g}$. Therefore, biochars with 384 macroporous structures were obtained under optimal conditions of pyrolysis. 

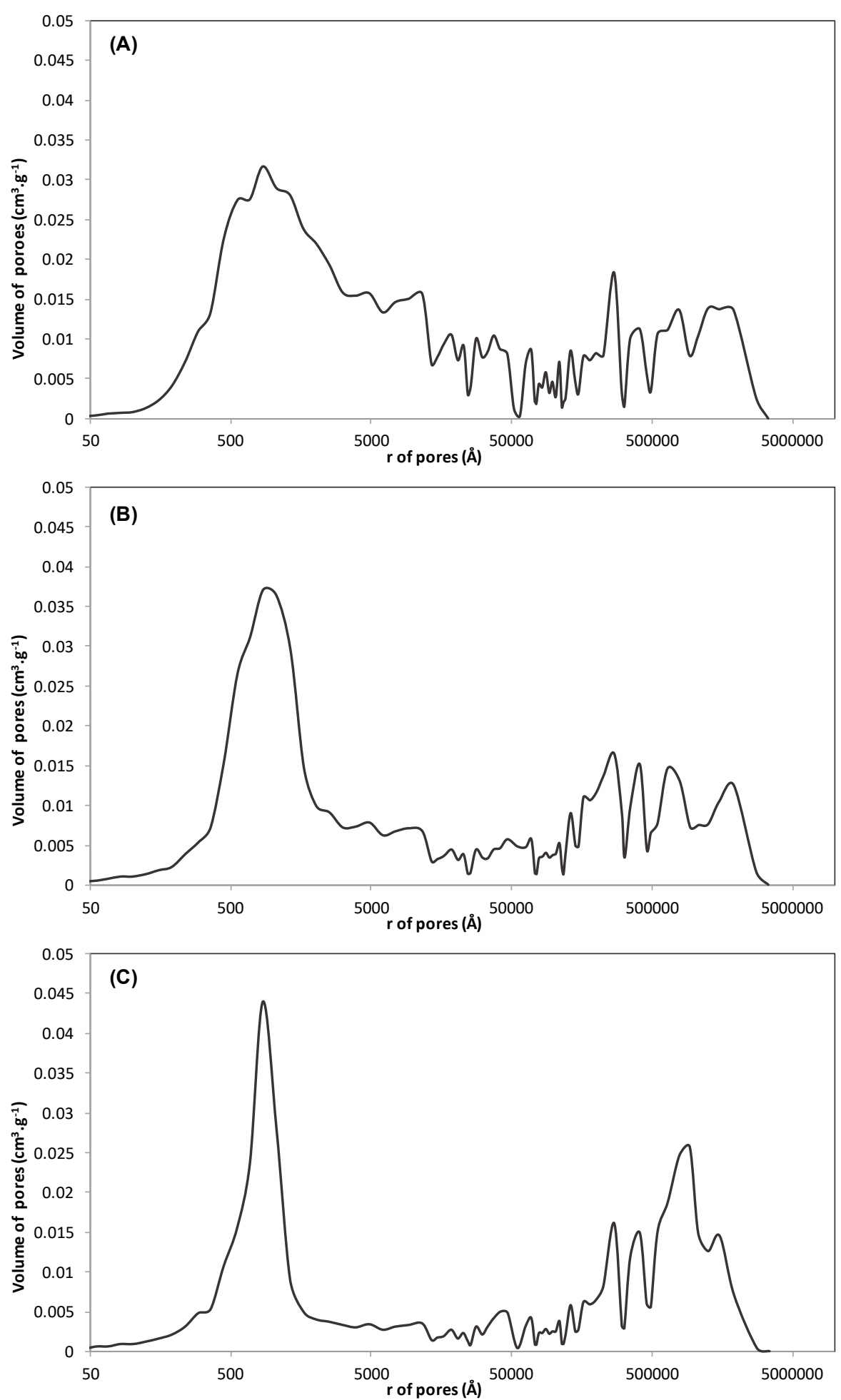

Figure 5. Pore size distribution curve for (A) BHB, (B) CCB, and (C) ALB. 
387

388

389

390

391

392

393

394

395

396

397

398

399

400

401

402

403

404

405

406

407

408

409

410

411 412

413

414 415

\section{0}

\section{1} 13 14

\subsection{X-ray diffraction (XRD)}

X-ray diffraction patterns of BHB, CCB, and ALB are shown in Figure 6. In the diffraction patterns of the three biochars, the amorphous response is observed from $2 \theta=10^{\circ}$, resulting from the heat treatment, forming a broad peak which can be attributed to the formation of cross-linked graphitic structures that form the carbon-pore structure. This finding indicates the presence of carbon-pore interfaces in the biochars, which is consistent with those reported by Prías-Barragán et al. (2011).

Peaks for $2 \theta$ around $28^{\circ}$ and $41^{\circ}$ were observed in BHB and CCB, which correspond to the peak (002) and the peak (100) of the graphite structure, respectively. According to Duan et al. (2016), these peaks show graphitization processes during pyrolysis. Thus, it can be established that the graphitization was slight since the peaks are not defined. The authors also explain that the broad peak at (002) could be the result of the incomplete development of microcrystalline structures, and the tiny peak at (100) could be attributed to the disordered graphite layers that were formed during the heat treatment. This second peak was more intense in the CCB (Figure 6B), followed by ALB (Figure 6C) and practically null in BHB (Figure 6A). Therefore, the peaks obtained in the diffractograms are indicative of the formation of graphite layers in the carbonaceous materials, mainly in CCB and ALB.Itcan be deduced from these peaks that the activated carbon is mostlikely amorphous and does not represent a crystalline structure.In contrast, the diffraction pattern of BHB shows peaks at approximately $21^{\circ}$ of $2 \theta$ than can be associated with the presence of amorphous $\mathrm{SiO}_{2}$ (Music et al., 2011; Shen et al., 2014). It represents a clear and consistent finding that in BHB are present amorphous silicon oxides. 


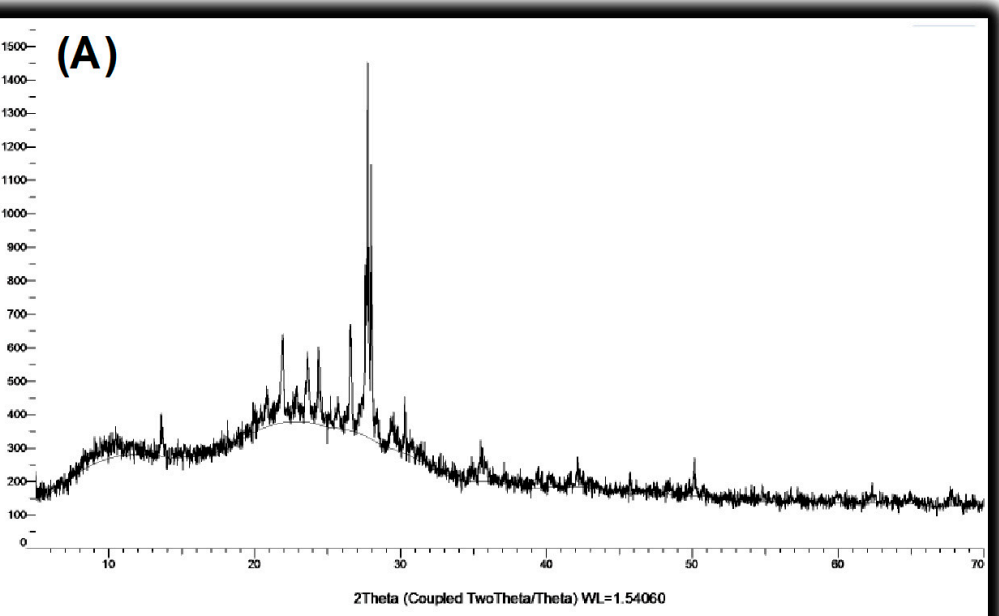

(B)

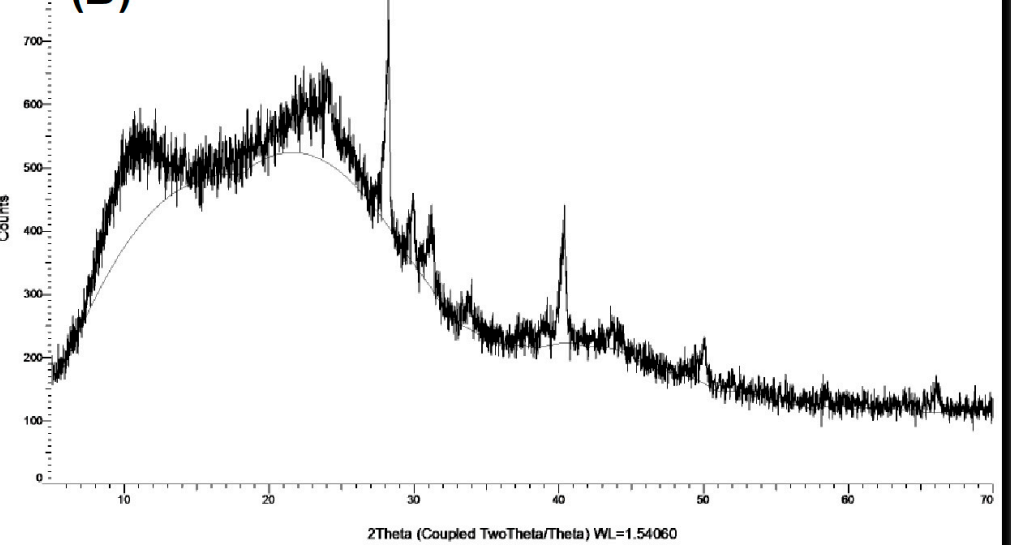

(C)

Figure 6. XRD pattern of (A) BHB, (B) CCB, and (C) ALB. 


\subsection{Thermogravimetric analysis (TGA)}

422 As a representative result of the thermogravimetric analysis, Figure 7 and Figure 8 shows 423 profiles of the fraction of the mass decrease of combustibles for precursors and biochars, 424 respectively. The vertical axis represents the fraction of mass decrease of combustibles. 425 From Figure 7, the thermal decomposition of lignocellulosic compounds starts at about 180 $426{ }^{\circ} \mathrm{C}$ for all the samples. As shown, the combustibles in the biomass react at the five stages 427 during the thermal decomposition (Nieto-Delgado and Rangel-Méndez, 2013). The first 428 phase at a temperature between $70^{\circ} \mathrm{C}$ and $150{ }^{\circ} \mathrm{C}$ was attributed to moisture released and to 429 the evaporation of some volatile compounds. The second stage was found from $180{ }^{\circ} \mathrm{C}$ to 430 about $230{ }^{\circ} \mathrm{C}$ and was attributed to the degradation of hemicellulose. At the third stage, the 431 mass rapidly decreases due to the cellulose volatilization. This stage was observed in the 432 temperature range of $250{ }^{\circ} \mathrm{C}$ to $350{ }^{\circ} \mathrm{C}$ for all the samples and was representative of the 433 thermal decomposition of cellulose. Thus, peaks at $299^{\circ} \mathrm{C}$ for $\mathrm{BH}$, at $300^{\circ} \mathrm{C}$ for $\mathrm{CC}$, and at $434326{ }^{\circ} \mathrm{C}$ for AL were observed. Similar behaviors have been reported in other studies for the 435 same precursors (Bagheri and Abedi, 2009; Bledzki et al., 2010; Nieto-Delgado et al., 436 2011; Espino et al., 2014). The fourth stage, between $380{ }^{\circ} \mathrm{C}$ and $550{ }^{\circ} \mathrm{C}$, was attributed to 437 the lignin decomposition. As shown in Figure 7, the thermogravimetric analysis for $\mathrm{BH}$, $438 \mathrm{CC}$, and AL demonstrate that cellulose is the major component in all precursors. This result 439 is because the three precursors showed high cellulose content and low lignin content as 440 shown in Table 1.

441 According to Gani and Naruse (2007), the cellulose decomposes in the temperature range 442 of $240-350{ }^{\circ} \mathrm{C}$ (Nieto-Delgado and Rangel-Méndez, 2013). In contrast, lignin is the 443 biomass fraction with the higher decomposition temperature $\left(280-500{ }^{\circ} \mathrm{C}\right)$, since part of 444 lignin consists of benzene rings, and is the fraction with higher carbon content (Gani and 445 Naruse, 2007; Nieto-Delgado and Rangel-Méndez, 2013).

446 The fifth stage was attributed to the ash derived from the degradation of complex polymers 447 and inorganic salts present in the precursors, mainly in BH and AL. These results are 448 consistent with those reported by Gani and Naruse (2007) who suggest that the thermal 449 behavior of biomass depends on its components such as the cellulose and lignin content. 
450 In the thermal decomposition profile of the biochars, a very discreet endothermic peak was 451 observed at temperatures below $100{ }^{\circ} \mathrm{C}$, attributed to desorption of physisorbed water 452 (Figure 8). For the biochars sample, the peak corresponding to cellulose and hemicellulose 453 degradation was not observed. It is a difference concerning the thermal decomposition 454 profile of the lignocellulosic residues. Finally, fluctuations occurring between 450 and 550 $455{ }^{\circ} \mathrm{C}$ were found in the thermal decomposition profile of biochars which can be attributed 456 toprolonged lignin degradation since this compound has high thermal stability (Figure 8). 457 This peak was more intense in the ALB since its precursor has the highest lignin content as 458 shown in Table 1.

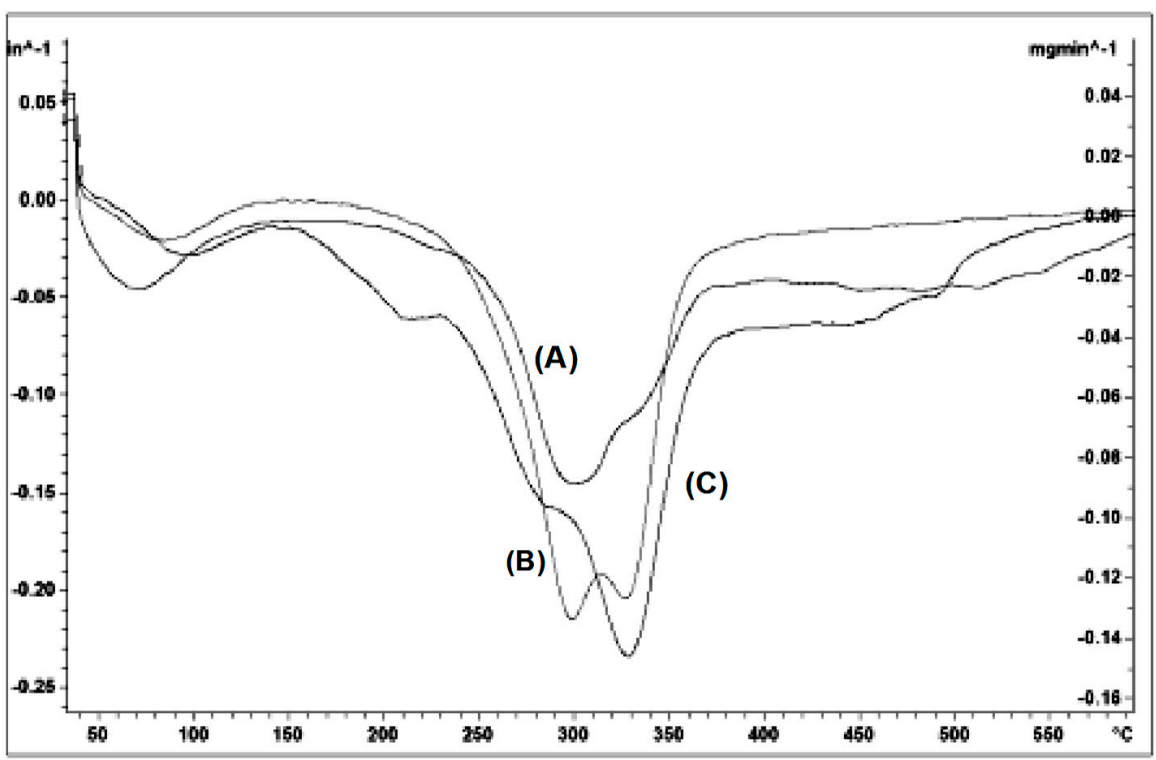

460 Figure 7. Thermogravimetric analysis of (A) BH, (B) CC, and (C) AL. 


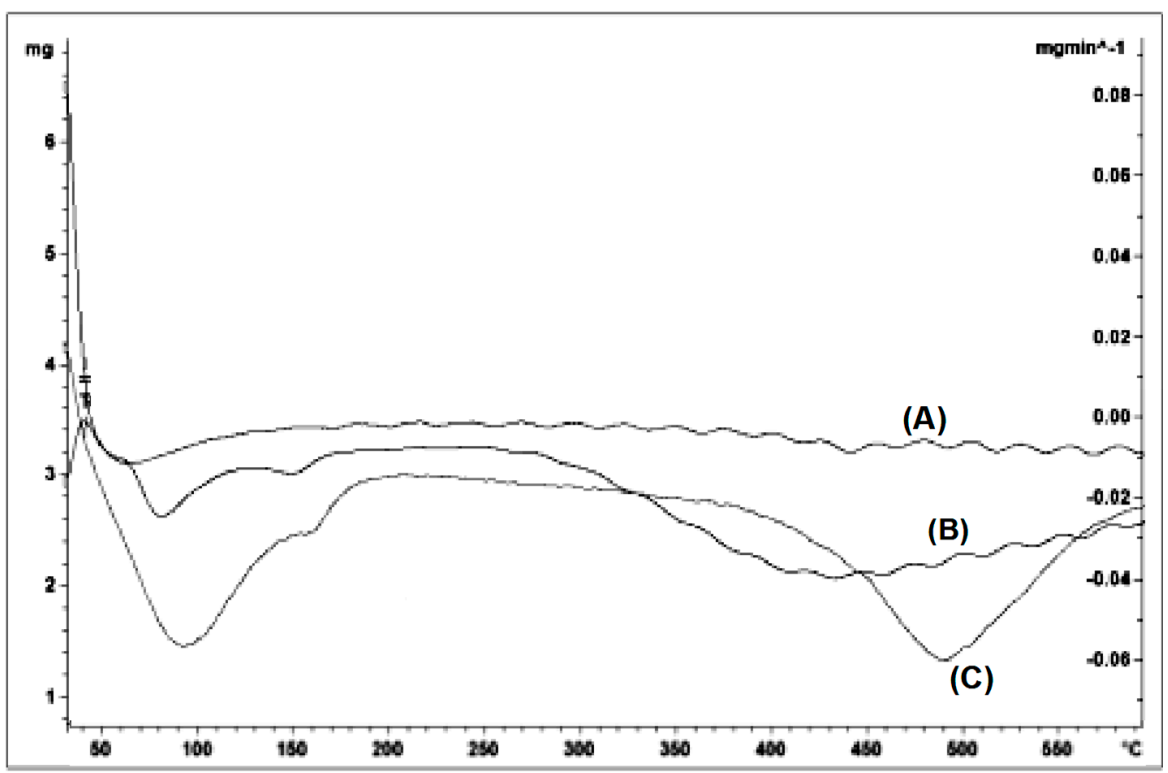

462 Figure 8. Thermogravimetric analysis of (A) BHB, (B) CCB, and (C) ALB.

463

464

465

466

467

468

469

470

471

472

473

474

475

476

477

478

479

480

481

\subsection{Zeta Potential}

The zeta potential is a physical parameter that can be used to quantify the electrical potential of the surface of a solid particle ( $\mathrm{Li}$ et al., 2003). According to the literature, the electrokinetic behavior of the activated carbons in solution is one of the most important properties in the characterization of these materials. It is also mentioned that these materials are amphoteric due to the presence of several functional groups on their surfaces and to delocalized electrons that confer fundamental properties (Chingombe et al., 2005). Thus, zeta potential measurements determined that the surface charge of the three biochars is anionic, obtaining values of $-34.40 \mathrm{mV}$ for BHB, $-48.02 \mathrm{mV}$ for $\mathrm{CCB}$, and $-29.00 \mathrm{mV}$ for ALB. It can be observed that CCB presented the highest value of anionic surface charge after the pyrolysis process, followed by ALB and ultimately BHB. From these results, it is established that the zeta potential values indicate the presence of anionic surfaces in the biochars obtained, mainly in CCB. Therefore, the biochars achieved in this study can be effective for adsorption processes of molecules or ions with positive surface charge.

\section{Conclusions}

Biochars were produced from barley husk, corn cob, and agave leaves. The effectof operating parameters on the biochar yield wasinvestigated. The experiments were based on 
482 Taguchi experimental design (L9). Theanalysis of variance made clear that the leading 483 factor was the activation time with about $50 \%$ effect on the biochar yield. The 484 optimumconditions obtained for maximum biochar yields were: carbonization temperature 485 of $400{ }^{\circ} \mathrm{C}$ (level 2), process time of $30 \mathrm{~min}$ (level 1), precursor mass of $2 \mathrm{~g}$ (level 1), and $\mathrm{N}_{2}$ 486 flow rate of $150 \mathrm{cc} / \mathrm{min}$ (level 2). Biochar yields of $19.75 \%$ for $\mathrm{CCB}, 32.88 \%$ for $\mathrm{BH}$, and $48731.14 \%$ for ALB were obtained at optimum conditions. Biochars with a predominantly 488 macroporous structure, amorphousstructure, numerous oxygen functional groups, anionic 489 surface and moderate ash content were obtained. The results of this investigation show that 490 barley husk, corn cob, and agave leaves are likely precursors for biochar production.

491

492

493

494

495

496

497

498

499

500

501

502

503

504

505

506

507

508

509

510

\section{Acknowledgements}

This work was supported by the National Council of Science and Technology (CONACyT) [doctorate scholarship number 289880].

\section{References}

Ahmad, M., Rajapaksha, A. U., Lim, J.E., Zhang. M., Bolan, N., Mohan, D., Vithanage, M., Lee, S.S., Ok, Y.S. (2014) Biochar as a sorbent for contaminant management in soil and water:A review. Chemosphere, 99:19-33.

ASTM Standard D3172, 1989, 1997. Standard Practice for Proximate Analysis of coal and coke. ASTM International, West Conshohocken, PA.

Ateş, F., Pütün, E., Pütüna, E. (2004) Fast pyrolysis of sesames talk: yields and structural analysis of bio-oil. J. Anal. Appl. Pyrol., 71:779-790.

Azizi, S.N., Dehnavi, A.R., Joorabdoozha, A. (2013) Synthesis and characterization of LTA nanozeolite using barley husk silica: Mercury removal from standard and real solutions. Mater. Res. Bulletin, 48:1753-1759.

Bagheri, N., Abedi, J. (2009) Preparation of high surface area activated carbon from corn by chemical activation using potassium hydroxide. Chem. Eng. Res. Des.,87:1059-1064. 
511 Bledzki, A.K., Mamum, A.A., Volk, J. (2010) Barley husk and coconut shell reinforced 512 polypropylene composites: The effect of fibre physical, chemical and surface properties. 513 Compos Sci Technol,70:840-846.

514 Bohli, T., Ouderni, A., Fiol, N., Villaescusa, I. (2015) Evaluation of an activated carbon 515 from olive stones used as an adsorbent from heavy metal removal from aqueous phases. 516 Comptes Rendus Chimie, 18:88-99.

517 Canales-Flores, R. A., Prieto-García, F. (2016) Carbonoceous materials from agricultural 518 waste. A review. Chem. Biodiversity, 13:261-268.

519 Chingombe, P., Saha., B., Wakeman, R.J. (2005) Surface modification and characterization 520 of a coal-based activated carbon. Carbon, 43:3132-3143.

521 Choi, H.S., Choi, Y.S., Park, H.C. (2012) Fast pyrolysis characteristics of lignocellulosic 522 biomass with varying reaction conditions. Renew Energy, 42:131-135.

523 Demirbas, A. (2004) Effect of initial moisture content on the yields of oily products from 524 pyrolysis of biomass. J. Anal. Appl. Pyrol.,71:803-815.

525 Duan, X., Srinivasakannan, C., Wang, X., Wang, F. Liu, X. (2016) Synthesis of activated 526 carbon fibers from cotton by microwave induced $\mathrm{H}_{3} \mathrm{PO}_{4}$ activation. J. Taiwan Inst. Chem. 527 Eng., 000:1-8.

528 Espino, E., Cakir, M., Domenek, S., Román-Gutiérrez, A.D., Belgacem, N., Bras, J. (2014)

529 Isolation and characterization of cellulose nanocrystals from industrial by-products of 530 Agave tequilana and barley. Ind. Crop. Prod.,62:552-559.

531 Gani A., Naruse, I. (2007) Effect of cellulose and lignin content on pyrolysis and 532 combustion characteristics for several types of biomass. Renew. Energ.,32:649-661.

533 Ioannidou, O., Zabaniotou, A. (2007) Agricultural residues as precursors for activated 534 carbon production-A review. Renew. Sust. Energ. Rev., 11:1966-2005.

535 Kirby, E.D. (2006) A Parameter Design Study in a Turning Operation Using the Taguchi 536 Method, pp. 1-14.

537 Kundu, A., Gupta, B.S., Hashim, M.A., Redzwan, G. (2014) Taguchi optimization 538 approach for production of activated carbón from phosphoric acid impregnated palm kernel 539 shell by microwaveheating, J. Clean. Prod., xxx: 1-8.

540 Li, Y.-H., Wang, S., Luan, Z., Ding, J., Xu, C., Wu, D. (2003) Adsorption of cadmium(II) 541 from aqueous solution by surface oxidized carbon nanotubes. Carbon, 41: 1057-1062. 
542 Loloide, Z., Mozaffarian, M., Solieman, M., Asassian, N. (2016) Carbonization and CO2

543 activation of scrap tires:Optimization of specific surface area by the Taguchi method, 544 Korean J. Chem. Eng., xxxx:1-10.

545 Musić, S., Filipović-Vinceković, N., Sekovanić, L. (2011) Precipitation of amorphous $\mathrm{SiO}_{2}$ 546 particles and their properties. Brazil. J. Chem. Eng., 28: 89-94.

547 Nieto-Delgado, C., Rangel-Méndez, J.R. (2013). Preparation of Carbon Materials from 548 Lignocellulosic Biomass. In: Rufford TE (ed) Green Carbon Materials. Advanced and 549 Aplications, Taylor \& Francis Group, US, pp. 51.

550 Nieto-Delgado, C., Terrones, M., Rangel-Mendez, J. R. (2011) Development of highly 551 microporous activated carbon from the alcoholic beverage industry organic by-products. 552 Biomass Bioenerg.,35:103-112.

553 Onay, O., Beis, S.H., Koçkar, O.M. (2001) Fast pyrolysis of rape seed in a well-swept 554 fixed- bed reactor. J. Anal. Appl. Pyrol, 58:995-1007.

555 Pereira, R.G., Martins, C., Mendes, N., Farias, L., Ferreira, R.C., Oliveira, A., Oliveira, M., 556 da Costa,R. (2014) Preparation of activated carbons from cocoa shells and siriguela seeds 557 using $\mathrm{H}_{3} \mathrm{PO}_{4}$ and $\mathrm{ZnCl}_{2}$ as activating agents for BSA and $\alpha$-lactalbumin adsorption. Fuel 558 Process. Technol.,126:476-486.

559 Pütün, A.E., Apaydin, E., Pütün, E. (2002) Bio-oil production from pyrolysis and steam 560 pyrolysis of soy bean-cake: product yields and composition. Energy, 27:703-713.

561 Prías-Barragán, J. J., Rojas-González, C. A., Echeverry-Montoya, N. A., Fhontal, G., 562 Ariza-Calderón, H. (2011) Identificación de las variables óptimas para la obtención de 563 carbón activado a partir del precursor Guadua Angustifolia Kunth. Rev. Acad. Colomb. 564 Cienc., 35:157-166.

565 Sensöz S., Angin D. (2008) Pyrolysis of safflower (Charthamus tinctorius L.) seed press 566 cake: part1. The effects of pyrolysis parameters on the product yields. Bioresour. Technol., 567 99:5492-5497.

568 Shen, Y., Zhao, P., Shao, Q. (2014) Porous silica and carbon derived materials from rice 569 husk pyrolysis char. Micropor. Mesopor. Mat., 188:46-76.

570 Stefanidis, S.D., Kalogiannis, K.G., Iliopoulou, E.F., Michailof, C.M., Pilavachi, P.A., 571 Lappas, AA. A study of lignocellulosic biomass pyrolysis via the pyrolysis of cellulose, 572 hemicellulose and lignin. J. Annal. Appl. Pyrol., 105:143-150. 
573 Shackley, S., Carter, S., Knowles, T., Middelink, E., Haefele, S., Sohi, S., Cross, A., 574 Haszeldine, S. (2012) Sustainable gasification-biochar systems? A case-study of rice-husk 575 gasification in Cambodia, Part 1: Context, chemical properties, environmental and health 576 and safety issues. Energ. Policy,42: 49-58.

577 Syed-Hassan, S.S.A., Md Saini, M.S. (2016) Optimization of the preparation of activated 578 carbon from palm kernel Shell for methane adsorption using Taguchi orthogonal array 579 design. Korean J. Chem. Eng., xxxx:1-11.

580 TAPPI T203 (1999) Alpha-, beta- and gamma-cellulose in pulp. TAPPI Press, Norcross, 581 Georgia.

582 TAPPI T204 (1997) Solvent extractives of wood and pulp. TAPPI Press, Norcross, 583 Georgia.

584 TAPPI T222 (1998) Acid-insoluble lignin in wood and pulp. TAPPI Press, Norcross, 585 Georgia.

586 Tripathi, M., Sahu, J.N., Ganesan, P. (2016) Effect of process parameters on production of 587 biochar from biomass waste through pyrolysis: A review. Renew. Sust. Energ. Rev., $588 \quad \mathbf{5 5}: 467-481$.

589 Wise L.E., Marphy M., d'Adieco A. (1946) A chlorite holocellulose, its fractionation and 590 bearing on summative wood analysis and studies on the hemicelluloses. Pap. Trade. $591 \quad J .122: 35-43$.

592 Xiong, S., Zhuo, J., Zhang, B., Yao, Q. (2013) Effect of moisture content on the 593 characterization of products from the pyrolysis of sewage sludge. J. Anal. Appl. 594 Pyrol.104:632-639.

595 Zhang H., Xiao R., Huang H., Xiao G. (2009) Comparison of non-catalytic and catalytic 596 fast pyrolysis of corn cob in a fluidized bed reactor. Bioresour. Technol., 100:1428-1434. 